be subsidized, largely by the member firms of the Slough Industrial Health Service. Now with a new Council of Management, Dr. Hickish the occupational hygiene engineer as Director, and other staff modifications, the service has been launched on its own. The Nuffield Foundation has given a grant of up to $£ 20,000$ over five years by which time the Service is expected to be a selfsupporting commercial proposition.

While the need for occupational hygiene services remains great especially in smaller factories, the demand increases slowly. Services such as the one at Slough, the North of England Industrial Hygiene advisory service based on Durham University and the one at Manchester University, will help to increase the demand and ascertain the best ways of meeting it. The new training courses for occupational health engineers at the London School of Hygiene and Tropical Medicine will help to train staff for these services. However, no other form of health service concerned with prevention has developed on a fee for service basis, and occupational hygiene is not likely to be an exception. This means that while large industrial organizations and a few others supported by the Nuffield Foundation may run successful occupational hygiene services the vast majority of industry will go without until some Government department-presumably the Ministry of Labour-undertakes its long overdue task.

\section{H. WooD}

Control of Airborne Dust. By W. D. Bamford. (Pp. viii +479 ; illustrated. $65 s$., to members of the Association; 84s. to non-members.) Birmingham: The British Cast Iron Research Association. 1961

This volume is a blend of reports of original work relating to the formation, movement, and control of dust clouds, and textbook material dealing with heating, fan engineering, and air cleaning. There is therefore a wealth of useful information for the engineer concerned with dust control.

The primary interest of the author has been the control of dust in foundries, and special attention is paid to thermal currents, knock-outs, and abrasive wheels. Nevertheless the principles enunciated should be capable of application to other dust and fume problems.

Experimental methods and results are given in detail, and while this does not make for ease of reading for the general reader it will probably be welcomed by those who use the book with a specific problem in mind.

\section{E. HICKISH}

Aktuelle Probleme der Staublungenforschung. Tagungsbericht zum 10, Kongress der Süddeutschen TuberkuloseGesellschaft in Beyreuth vom 1, bis 3, Juni 1961. Edited by H. Hofmann. (Pp. 163; 74 figures + tables. DM. 13.80.) Stuttgart: Georg Thieme. 1962.

Some 14 papers by eminent German authorities on dust disease are presented in this volume along with some short reports of the discussion. Very many of the medical aspects of the pneumoconiosis problem are touched on, and some papers range over a great part of the subject. Some points of special interest are: special types of pneumoconiosis; bronchitis and emphysema in persons exposed to dust, silico-tuberculosis; and prophylaxis and treatment of dust disease of the lungs. One special type of pneumoconiosis becoming more common presents radiologically a very fine diffuse generalized nodulation, a lattice-net appearance, which may be better seen by the use of a special $x$-ray technique. This "pin-head" type is due to mixed dust containing much coal dust with little silica, and by damaging the pulmonary circulation leads to right heart failure. A second type of pneumoconiosis, Caplan's syndrome, is discussed by Dr. Worth and Dr. Fritze. Dr. Sepke states that reticulum cells appear in the blood in 80 to $90 \%$ of such cases to the extent of about 2 to $11 \%$, but are rarely found in the blood of ordinary silicotic patients. The third type of interest is that presenting egg-shell calcification of the hilus, without nodulation. Dr. Ahlendorf puts in a plea that this type should be recognized for compensation purposes as silicosis causing disability. His cases largely occur in slate workers.

Bronchitis and emphysema and their sequelae in workers exposed to dust are naturally mentioned by many of the contributors and are the subject of two papers. Dr. Carstens in a discussion gives his view that dust lung disease is not merely silicosis but is a complex of specific and unspecific reactions of the lung to dust, which are independent in their causes. This complex includes silicosis, asthmatic emphysema, bronchitis, bronchiectasis, and probably atrophy resulting from the dust. The whole question of the relation of dust inhalation to bronchitis and emphysema is reviewed in a paper by Dr. H. Valentin. The conclusion he draws is that a causal connexion between the two has not been proved.

Silico-tuberculosis is compensatable Disease No. 35 in the new 6th Regulation. It is entitled "Silicosis combined with active tuberculosis", a definition which differs from that of the previous 5th Regulation which used the expression "active-progressive tuberculosis". This point as well as many other features of the combined disease is thoroughly discussed by various contributors. However silico-tuberculosis in modern times is much less frequent in trades such as the pottery, moreover the addition of tuberculosis does not lessen the expectation of life of silicotics as it did. The treatment of tuberculosis in the presence of silicosis is difficult and Dr. H. Roth says that conservative treatment to be successful must be started as soon as tuberculosis is suspected, and should be intensive and persisted in from eight to $\mathbf{4 8}$ months. But $60 \%$ of patients receive none or only temporary benefit from chemotherapy, so operative measures are employed and nowadays that means resection. On the results of this treatment in pottery workers, which are not very encouraging, Roth makes an appeal for the institution of prophylactic measures.

Treatment and medical prophylaxis are dealt with by Dr. J. Klippel in a very comprehensive way. Methods developed from modern investigations into silicosis such as cortisone treatment, aluminium inhalation, aerosol treatment, have not proved very successful. The symptomatic treatment of the various complications, bronchitis and emphysema, bronchiectasis and so on up to right heart failure are considered very fully, especially from the 